\title{
COVID-19: Possible Cause of Induction of Relapse of Plasmodium vivax Infection
}

\author{
Rashmi Kishore $^{1}$ (I) $\cdot$ Shivram Dhakad ${ }^{2} \cdot{\text { Nazneen } \text { Arif }^{2} \cdot{\text { Lalit } \text { Dar }^{2}}^{2} \text { B. R. Mirdha }}^{2} \cdot$ Richa Aggarwal $^{3} \cdot$ S. K. Kabra ${ }^{1}$
}

Received: 19 June 2020 / Accepted: 25 June 2020 / Published online: 3 July 2020

(C) Dr. K C Chaudhuri Foundation 2020

To the Editor: In ongoing pandemic of novel corona virus disease (COVID-19), clinicians are observing atypical manifestations of the disease. We hereby report a case of COVID19 co-infection with vivax malaria in a 10 -y-old boy, who previously had received incomplete radical cure with primaquine for vivax infection, suggesting a possible role of COVID-19 in inducing current malarial relapse.

A 10-y-old boy, resident of Delhi, presented to the pediatric emergency department of a tertiary care hospital with history of high grade fever with chills and rigors, headache, cold, cough and pain abdomen. Past history revealed admission with a similar episode of febrile illness six months back. Medical records from previous admission revealed that he was diagnosed with $P$. vivax infection and had not completed primaquine therapy as per history. At presentation, child was febrile with fever of $104^{\circ} \mathrm{F}$, maintained saturation of $97-98 \%$ on room air. Rest of systemic examination was normal. Investigations revealed $\mathrm{Hb}$ of $11.7 / \mathrm{dl}$, total leucocyte count (TLC) of $4500 / \mathrm{mm}^{3}$ with $15 \%$ neutrophils, $53 \%$ lymphocytes and $28 \%$ eosinophils (absolute eosinophil count of $1260 / \mathrm{mm}^{3}$ ), and platelet count of $52,000 / \mathrm{mm}^{3}$. Rapid diagnostic test for malaria was faintly positive for pan antigen and smear examination showed all stages of Plasmodium $\operatorname{vivax}(P$. vivax), confirming it to be malaria. Nasal and pharyngeal swabs RT-PCR for corona virus 2 (SARS-CoV-2) were positive. Other investigations were normal.

Rashmi Kishore

rashmi.k186@gmail.com

1 Department of Pediatrics, All India Institute of Medical Sciences, New Delhi 110029, India

2 Department of Microbiology, All India Institute of Medical Sciences, New Delhi, India

3 Departmet of Anesthesiology, Critical and Intensive Care, JPNA Trauma Centre, All India Institute of Medical Sciences, New Delhi, India
The child was admitted and treated for malaria and supportive care for COVID-19 infection [1]. Primaquine eradication therapy was given for $14 \mathrm{~d}$ after ruling out G6PD deficiency. He was discharged after complete recovery.

This boy had been diagnosed with $P$. vivax infection six months back and had now reactivation of malaria. Relapse rates after $P$. vivax infection vary geographically from 8 to $80 \%$, with considerable proportion of population harboring dormant but activatable hypnozoites in endemic areas [2]. Exact mechanism causing this activation is though unclear, associated cytokine response with systemic illness has been postulated in $P$ vivax relapse [3]. COVID-19 leads to a cytokine storm, which is responsible for the more severe manifestations of the disease $[4,5]$. Hence, we postulate that the COVID-19 infection, with its cytokine response was responsible for induction of $P$. vivax relapse in our patient. Our hypothesis is based on circumstantial evidence in form of documented malaria in past, a possibility of re-activation in natural course or re-infection cannot be ruled out.

Acknowledgments Director General, Indian Council of Medical Research, for providing funding for support of diagnostics.

\section{Compliance with Ethical Standards}

Conflict of Interest None.

\section{References}

1. Sankar J, Dhochak N, Kabra SK, Lodha R. COVID-19 in children: clinical approach and management. Indian J Pediatr. 2020;87:43342.

2. World Health Organization. Guidelines for the Treatment of Malaria. 2015. Available at: https://www.who.int/docs/default-source/ documents/publications/gmp/guidelines-for-the-treatment-ofmalaria-eng.pdf?sfvrsn=a0138b77_2. Accessed 19 May 2020.

3. White NJ. Determinants of relapse periodicity in plasmodium vivax malaria. Malar J. 2011;10:297. 
4. Guo YR, Cao QD, Hong ZS, et al. The origin, transmission and clinical therapies on coronavirus disease 2019 (COVID-19) outbreak-an update on the status. Mil Med Res. 2020;7:11.

5. Xu Z, Shi L, Wang Y, et al. Pathological findings of COVID-19 associated with acute respiratory distress syndrome. Lancet Respir Med. 2020;8:420-2.
Publisher's Note Springer Nature remains neutral with regard to jurisdictional claims in published maps and institutional affiliations. 